\title{
Running in Quicksand: Environmental Change, Migration, and the Policy Imperatives
}

\author{
Kelly M. McFarland ${ }^{1}$
}

Published online: 13 July 2017

(C) Society for International Development 2017

\begin{abstract}
Environmental change increasingly effects internal and external patterns of human movement around the globe. Whether due to loss of livelihood from rising sea waters, degradation of arable land, or increased frequency and severity of storms, people are on the move. This article looks at environmental factors driving this new wave of migrants and provides a set of 'guiding principles' for policymakers, international institutions, NGOs, academia, and the think tank community to create new policies, and the obstacles they may face in implementation.
\end{abstract}

Keywords Environment $\cdot$ Climate $\cdot$ Migration $\cdot$ Refugee $\cdot$ Migrant · Human security

Climate change and shifting weather patterns are not the Tinker Bells of science or of policy. Disbelief, or denial, a suspension of research, or American withdrawal from the Paris Climate Accord will not make melting icecaps, rising sea levels, desertification, and floods go away. There may be legitimate debate on the pace of these changes, or whether there is a meaningful difference between the degrees of global warming that will result in inconvenient, catastrophic, or apocalyptic scenarios. But the empirical data is there. There is change and it affects human security - which will influence where humans live-and whether they must abandon their homes. As people are forced to migrate simply to survive, we face the possibility of

Kelly M. McFarland

Kelly.McFarland@georgetown.edu

1 Washington, DC, USA major shifts in human settlement patterns, along with increased competition for resources. ${ }^{1}$

Designated a US national security issue for a decade or more, climate change is more than swamped islands and weird weather. ${ }^{2}$ Environmental changes shape internal and external patterns of human movement around the globeboth sudden, large-scale displacement and the more difficult to track slow-onset migration-through their influence on a broad range of economic, social, and political drivers (Foresight: Migration and Global Environmental Change 2011: 6; Martin 2013). This article focuses on the human side of climate change, specifically investigating slow-onset migration-when families and communities can no longer support themselves because of local environmental changes - and seeks to answer the question of what new

\footnotetext{
1 This article is an edited version of the Institute for the Study of Diplomacy's April 2017 report: 'New Challenges to Human Security: Environmental Change and Human Mobility.' https://georgetown. app.box.com/s/punu9t0hczjan0w7iu1jfhxfk01ywcyc. With generous support from the Carnegie Corporation of New York's 'Bridging the Gap' initiative, in October 2016 the Institute for the Study of Diplomacy launched a two-year working group series entitled 'The New Global Commons: Emerging Global Diplomatic Challenges.' Bringing together senior practitioners, policymakers, and leading academics, the series harnesses the experience and collective knowledge of this broad range of experts to discuss and find workable policy solutions and guiding principles to some of the world's most pressing issues through the end of the decade and beyond. Over the course of two meetings in the fall of 2016, the series' first working group looked at the little-understood issue of environmental change and migration.

2 See, for instance, An Abrupt Climate Change Scenario and its Implications for United States National Security (http://oai.dtic.mil/oai/ oai?verb=getRecord \&metadataPrefix $=$ html\&identifier $=$ ADA469325), a 2003 report from the Department of Defense Office of Net Assessment; or the 2008 National Intelligence Assessment on the National Security Implications of Global Climate Change to 2030 (https://fas.org/irp/congress/2008_hr/062508fingar.pdf).
} 
policy tools do states and organizations, individually and collectively, need to guide the most constructive forms of mobility and migration?

\section{Introduction}

Environmental and climatic change, including more intense storms, rising sea levels, record-breaking temperatures, increased droughts exacerbated by over-consumption of water, and myriad other climate-related changes, are likely to affect growing numbers of people around the world. Jon Barnett and W. Neil Adger, climate change scholars, summarize the critical problem:

Climate change increasingly undermines human security in the present day, and will increasingly do so in the future, by reducing access to, and the quality of, natural resources that are important to sustain livelihoods. Climate change is also likely to undermine the capacity of states to provide the opportunities and services that help people to sustain their livelihoods (Barnett and Adger 2007: 639).

In a sweeping 2014 report, the Intergovernmental Panel on Climate Change (IPCC) noted that climate change has significantly affected humans and ecosystems across the planet in recent decades. More specifically, the IPCC (2014) report notes:

- In many regions, changing precipitation or melting snow and ice are altering hydrological systems, affecting water resources in terms of quantity and quality. Glaciers continue to shrink almost worldwide due to climate change, affecting runoff and water resources downstream... Climate change is causing permafrost warming and thawing in both high-latitude and highelevation regions (IPCC 2014: 4).

- Climate change over the twenty-first century is projected to reduce renewable surface water and groundwater resources significantly in most dry subtropical regions, intensifying competition for water among sectors (IPCC 2014: 14).

Our changing global climate has an increasing impact on migration trends around the world. It can be difficult to pinpoint the precise reasons people seek to migrate. The catalyst for people leaving their homes (i.e., the drivers of migration) initially may reflect one reason-to seek better economic opportunities, perhaps. By the time migration actually occurs, the situation may be more complex. Drivers can happen in any order and other factors can be at play, but the result is the same: People leave their homes.

\section{Environment and Migration: The Connection}

First, increased competition over natural resources make conditions ripe for wide-scale displacement. A host of nations between now and 2022, according to a 2012 US National Intelligence Council (NIC) report on Global Water Security, 'will experience water problems-shortages, poor water quality, or floods - that will risk instability and state failure' and 'increase regional tensions.' Expanding out to 2040, the same report predicts that 'fresh water availability will not keep up with demand absent more effective management of water resources. Water problems will hinder the ability of many countries to produce food and generate energy, posing a risk to global food markets and hobbling economic growth' (The National Intelligence Council 2012: iii).

Environmental changes may have lengthened the growing season and boosted the acreage of arable land in higher-altitude regions, but crop yields worldwide, particularly for wheat and maize, are likely to be negatively affected (IPCC 2014: 5-6). The IPCC study also notes that, while not yet as severe as its effects on other sectors, 'local changes in temperature and rainfall have altered the distribution of some water-borne illnesses and disease vectors' (IPCC 2014: 6). As we contemplate both environmental change and migration that stems from it, we must also keep issues of health and disease-linked both to changes in climate/weather patterns and to changes in human settlement patterns-front and centre.

As environmental changes exacerbate resource shortages, conflict over those resources is likely to prompt migration to safer havens - but may then create conflicts in new host communities coping with an influx of migrants. Migration scholar Susan Martin points out, for instance, that 'competition for increasingly scarce resources may lead to a higher incidence of human conflict (Martin 2013: 1).

The relationship between climate change and conflict also has direct US national security implications. As the NIC notes in a September 2016 report on Implications for US National Security of Anticipated Climate Change,

even if climate-induced environmental stresses do not lead to conflict, they are likely to contribute to migrations that exacerbate social and political tensions, some of which could overwhelm host governments and populations (The National Intelligence Council 2016).

Moreover, the report continues, 'over 20 years, the net effects of climate change on the patterns of global human movement and statelessness could be dramatic, perhaps unprecedented.' (The National Intelligence Council 2016).

Longer-term global drying trends will continue to spur migration as growing numbers of communities struggle 
with crop losses and disruption of pastoral livelihoods. Prolonged droughts have also exacerbated recent conflicts in both Darfur and Syria. In Darfur, in particular, as groups moved out of drought-ridden areas, 'the new arrivals' need for land-both for agriculture and grazing-caused tension, which slowly escalated into outright hostility and eventually the explosive violence beginning in 2003' (Null and Herzer Risi 2016: 21). ${ }^{3}$ Likewise, conflict between Fulani herders and Nigerian farmers continues, as the Fulani's continued search for grazing lands pushes them further South onto farm lands.

Second, extreme weather events are more frequent and more intense. In the near term, climate changes related to global warming appears linked to extreme weather events such as cyclones, storm surges, and greater variability in rainfall, along with greater incidences of weather-related disruptions. These types of events highlight the vulnerabilities to weather volatility within both ecosystems and human systems.

The IPCC (2014) report notes:

Impacts of such climate-related extremes include alteration of ecosystems, disruption of food production and water supply, damage to infrastructure and settlements, morbidity and mortality, and consequences for mental health and human well-being. For countries at all levels of development, these impacts are consistent with a significant lack of preparedness for current climate variability in some sectors (IPCC 2014: 6).

The report also cautions that many communities are at risk from extreme weather events, which can cause a 'breakdown of infrastructure networks and critical services' (IPCC 2014: 13). Acute weather-related events make conditions ripe for wide-scale displacement.

Yemen is a case-in-point of these phenomena. A country that rarely sees typhoons, Yemen experienced two extremely severe storms in 2015, exacerbating the country's already catastrophic humanitarian situation. Yemen also highlights a key point, those most effected by environmental change and most vulnerable to the demand to migrate are most often those too poor to do so.

In many parts of the world the management of resources, both before shortages become an issue and after, has emerged as a major factor in a group or region's ability to cope with environmental change. In South Asia, for instance, shifting weather patterns and overuse of groundwater have forced many people out of their homes and away from their communities, temporarily or permanently.

\footnotetext{
3 This report also links the conflict in Syria to drought conditions: 'in the late $2000 \mathrm{~s}$ prior to the uprising, a three-year drought - the most severe on instrumental record-caused large-scale food and livelihood insecurity and displaced up to 1.5 million Syrians' (Null and Herzer Risi 2016: 25).
}

Some Indian families send their children abroad for study-effectively using education as a form of pre-emptive migration. Some low-lying Pacific Islands governments include job training programs as part of their overall resilience planning, allowing islanders to transition to nonagricultural work in Australia and New Zealand.

Third, rising sea levels create a range of problems. On a global scale, continued rising sea levels over the remainder of this century will cause increased flooding, submergence, saltwater intrusion into aquifers and deltas, and coastal erosion of low-lying areas and coastal systems. These types of climate change-related damage are particularly troubling because, as the IPCC (2014) report notes,

the population and assets projected to be exposed to coastal risks as well as human pressures on coastal ecosystems will increase significantly in the coming decades due to population growth, economic development, and urbanization (IPCC 2014: 17).

Rapid population growth and poor living conditions in many of the world's large littoral cities, moreover, only increase the potential for humanitarian disasters.

Susan Martin notes that 'rising sea levels and glacier melt may make coastal or low-lying areas uninhabitable' (Martin 2013: 1). The likely outcome, according to Martin, is a greater incidence of 'slow-onset migration, in which people seek new homes and livelihoods over a lengthy period of time as conditions worsen' (Martin 2013: 1). From the Mekong Delta to the Maldives and dozens more island chains, and in coastal zones from Bangladesh to Alaska and Louisiana, homes and livelihoods are at risk.

\section{What Can, and Should, Be Done?}

The risks and circumstances inherent in doing nothing to adapt and/or mitigate against the environmental change threat are apparent. Moreover, future energies should focus on issues related to mitigation and adaptation policies regarding slow-onset migration-both internal and external. This is an area where there has been far less policy work. There is of course a need for governments and the international community to continue to respond with disaster relief efforts.

There also is an urgent need for a coordinated approach to planning and response mechanisms related to specific and workable policy recommendations on long-term environmental migration. This is not to negate important work taking place in government agencies, NGOs, and international institutions. Rather, it is to call for a more integrated approach.

As the international community begins to plan for and devise strategies to deal with environmental migration, it is 
imperative that policymakers keep both ends of the migration path in mind. There are multiple issues and problems to plan for-in both outgoing and receiving communities - to make the migration process as smooth as possible from start to finish.

An even larger issue, and one exacerbated by the recent US election and the Trump administration's policies on climate science and climate change mitigation, is that many countries generally do not view issues related to the environment and human mobility as a tier-one priorityalthough many governments consider mass refugee and migration flows critical issues. There is an opportunity (and even more so now an imperative) for governments, as well as the United Nations and other international organizations and the NGO community, to work together to 1) define the problem, and 2) problem-solve on strategies to mitigate the impacts of slow-onset migration.

With this in mind, the following are a set of 'Guiding Principles' for all of these institutions to use when creating mitigation and adaptation policies, as well as strategies for longer-term, slow-onset migration.

- Define 'environmental migrants' - Universally accepted definitions of people who leave their homes for environmental reasons are important for a host of legal, economic, and security reasons. The international community must work to create definitions for these people that are socially and legally acceptable to all. ${ }^{4}$

- Collect more data - There is an urgent need for a coordinated push for real and useable data and new research on environmental change as a driver of migration, which groups and societies are hit the hardest, the efficacy of resiliency interventions, and how to assist vulnerable populations that may not be able to raise the funds to migrate. Do drought insurance plans or new irrigation technologies ease the 'push' factors that are likely to force struggling agricultural communities to relocate, for instance? More research is also needed on where people are heading — or where we think they will be going. Getting the answers to these, and other pressing questions, will make the planning process easier in the future.

- Consider the advantages of 'planned relocation' Planned relocation can be a positive and highly viable future alternative to ad hoc migration, done on the fly as a last resort. Working group participants reiterated that planned relocation will likely become more common in

\footnotetext{
${ }^{4}$ A clear lexicon of terms is important, particularly with regard to those who migrate primarily for environmental reasons. Conventional definitions of 'refugee' vs. 'migrant' are problematic, as they can create ambiguity in terms of international obligations-and, potentially, state assistance and other services-as well as how the world views these individuals and groups.
}

the future. The Institute for the Study of International Migration at Georgetown University, along with the Brookings Institution and the UNHCR, produced a paper on 'Guidance on Protecting People From Disaster and Environmental Change Through Planned Relocation.' The paper defines planned relocation as:

A planned process in which persons or groups of persons move or are assisted to move away from their homes or places of temporary residence, are settled in a new location, and provided with the conditions for rebuilding their lives. Planned Relocation is carried out under the authority of the State, takes place within national borders, and is undertaken to protect people from risks and impacts related to disasters and environmental change, including the effects of climate change. Such Planned Relocation may be carried out at the individual, household, and/or community levels. ${ }^{5}$

- At the same time, planned relocation is a highly complex issue with a large number of moving parts that can include different government entities, different nations, and disparate ethnic or socioeconomic groups. As such, this concept warrants further study and planning.

- Make development assistance more adaptive Development projects are not necessarily adaptive to sudden environmental change. Becoming more attuned to the signs that communities are likely to migrate is a first step in recognizing that a project may need to shift gears And the national governments, NGOs, and international organizations can reframe and rethink the development planning process to reduce each project's potential risk from extreme weather events, for instance. Also, they can prioritize those projects designed to assist communities that are most threatened by climate change.

- Create regional agreements - The international community should seek the creation of regional efforts that would allow for more fluid and workable migration. Dealing with some environmental-related problems on a regional basis will help make these issues more workable. In many instances of external migration, migrants are likely to traverse multiple international boundaries, with potential legal and security ramifications. At other times, those seeking to cross

\footnotetext{
5 The Brookings Institution, Georgetown University, Institute for the Study of International Migration, and Office of the United Nations High Commissioner for Refugees (7 October 2015) 'Guidance on Protecting People From Disaster and Environmental Change Through Planned Relocation,' https://isim.georgetown.edu/sites/isim/files/files/ upload/GUIDANCE_PLANNED\%20RELOCATION_14\%20OCT\% 202015.pdf, accessed June 27, 2017.
} 
borders will be hampered by neighbouring countries' regulations and policies.

- Develop regional 'safety valves' - Planning regionally for one nation or nations to serve as a safety valve for environmental migrants within a region. This would allow each region, and potentially the international community, to create workable incentives for these safety valve nations - and provide the financial, political, and logistical support these countries may need.

- Manage resources and infrastructure needs effectively - For communities receiving environmental migrants, managing resources and infrastructure will be just as vital to these communities to absorb an influx of newcomers. With adequate management of water and land resources in normal times, some communities at risk may not have to leave their homeland when extreme events occur. Building up the local physical and institutional infrastructure may enable people to continue making a living and remain in place despite the more frequent environmental stressors-and permit additional mitigation and adaptation options.

- Use 'pull' rather than 'push' mechanisms to steer migrants where their needs can best be met - Most environmental migrants move to already over-populated and environmentally endangered urban areas. The identification of regions and cities to serve as suitable landing spots for environmental migrants from both the regional/cities' perspective and the migrant's perspective is needed. This will allow for the creation of 'pull' mechanisms that steer environmental migrants to these cities/regions, while relaxing the pressure on some of the more over-populated migrant destinations.

- Focus on migrants' needs in the receiving communities - When environmental migrants relocate to urban areas, there are localized consequences: The majority of receiving communities likely also face many of the same environmental and economic challenges that forced migrants out of their home regions. And there may be significant ethnic or cultural challenges with large numbers of incoming environmental migrants. Too often, countries perceive migrants as a burden on receiving communities. However, migrants also can provide highly valued labour, both skilled and unskilled, as productive members of the local and national economy.

- Prioritize the creation of jobs within receiving communities - The globe is seeing a continued urban population explosion, particularly within coastal areas that are already highly vulnerable to climate change and environmental stresses. This increase in population, though, often does not come with an increase in the number of urban jobs, or a boost in economic growth, which has dire consequences as it relates to a potential influx of migrants to cities. This 'urbanization without growth' will have severe long-term consequences at both the local and global level, and offer few opportunities for environmental migrants heading to cities in the medium to long term.

\section{Conclusion}

Implementing these principles will not be easy. Data collection and research face funding constraints and academic priorities. Others-regional safety valves, for instancedemand political will and budget demands. Policy formulation, data collection and implementation is also not only state-level obligations but will demand the concerted attention of the NGO, think tank, and academic community.

Moreover, the current international political environment is not necessarily geared toward complex, globallybased and humanitarian-focused issues. The current United States administration's withdrawal to an 'America First' policy, its disdain for science, and an unwillingness to accept the realities of climate change, coupled with a disinterest in humanitarian or other non-kinetic issues has left the world without a leader in this area - at least until others step forward as they well do. A rising nativism around the globe is also leading groups and governments to recoil from anything that has to do with 'migrants'. But there is still hope. The international community, while facing a crisis of confidence over the trajectory of the international system, is capable of organizing around transnational issues such as climate change. The recent response from cities, states, leaders, and nations to Washington's announcement of withdrawal from the Paris Agreement are a case in point.

Although difficult to enact, without serious consideration and action on recommendations like those listed above will leave us - all of us globally - in perilous situation in the future. Denial of that reality does not make it any less real. The time is now to build resilience within communities most likely to be affected and those most likely to be receiving communities, and to focus on the longer-term, adaptive policies geared toward slow-onset migration and urbanization. Both are significant undertakings, but with the appropriate policies in place, policymakers have the potential to mitigate the harshest challenges of environmental changes, and guide human migration events along a more rational basis. This is in our core national interest, and of our own generations to come. 


\section{References}

Barnett, Jon and W. Neil Adger. 2007. Climate change, human security, and violent conflict. Political Geography 26: 639-655.

Foresight: Migration and Global Environmental Change. 2011. Final Project Report: Executive Summary. London: The Government Office for Science.

IPCC. 2014. Summary for Policymakers. In Climate Change 2014: Impacts, Adaptation, and Vulnerability, Part A: Global and sectoral aspects, contribution of Working Group II to the fifth assessment report of the intergovernmental panel on climate change, Christopher B. Field, Vicente R. Barros, David Jon Dokken, Katherine J. Mach, Michael D. Mastrandrea, T. Eren Bilir, Monalisa Chatterjee, Kristie L. Ebi, Yuka Otsuki Estrada, Robert C. Genova, Betelhem Girma, Eric S. Kissel, Andrew N. Levy, Sandy
MacCracken, Patricia R. Mastrandrea and Leslie L. White. Cambridge: Cambridge University Press.

Martin, Susan F. 2013. Environmental Change and Migration: What We Know. Migration Policy Institute Policy Brief 2: 1-2.

Null, Schuyler and Lauren Herzer Risi. 2016. Navigating Complexity: Climate, Migration, and Conflict in a Changing World. Woodrow Wilson International Center for Scholars: 1-44.

The National Intelligence Council. 2012. Global Water Security. Intelligence Community Assessment 2012-08.

The National Intelligence Council. 2016. Implications for US National Security of Anticipated Climate Change. https://www. dni.gov/files/documents/Newsroom/Reports\%20and\%20Pubs/ Implications_for_US_National_Security_of_Anticipated_Climate_ Change.pdf. Accessed 27 June 2017. 